Short Communication

\title{
Effect of Surface Roughness on the Corrosion Behavior of Pure Iron in Acidic Solutions
}

\author{
Ahmed S. Alshamsi ${ }^{*}$ and Afra AlBlooshi \\ Department of Chemistry, College of Science, United Arab Emirates University, Al Ain, UAE \\ *E-mail: a.alshamsi@uaeu.ac.ae
}

doi: $10.20964 / 2019.06 .64$

Received: 28 August 2018 / Accepted: 18 February 2019 / Published: 10 May 2019

The effect of surface roughness on the corrosion behavior of pure iron in acidic solutions (hydrochloric and sulfuric acids) in the absence and presence of molybdate ions was thoroughly investigated. Polarization techniques, electrochemical impedance spectroscopy, and scanning electron microscopy were used for this investigation. The results demonstrated that increasing surface roughness and the presence of molybdate ions have detrimental effects on the corrosion resistance of pure iron in acidic solutions. While general corrosion was observed at the open circuit potential, crystallographic pits were observed under anodic polarization in hydrochloric acid solutions.

Keywords: iron, corrosion, EIS, roughness, molybdate, $\mathrm{HCl}, \mathrm{H}_{2} \mathrm{SO}_{4}$.

\section{$\underline{\text { FULL TEXT }}$}

(C) 2019 The Authors. Published by ESG (www.electrochemsci.org). This article is an open access article distributed under the terms and conditions of the Creative Commons Attribution license (http://creativecommons.org/licenses/by/4.0/). 